Article

\title{
The Influence of BMSs on the Characterization and Modeling of Series and Parallel Li-Ion Packs
}

\author{
Sandra Castano-Solis ${ }^{1, *}$, Daniel Serrano-Jimenez ${ }^{2}$, Lucia Gauchia ${ }^{3}$ and Javier Sanz ${ }^{2}$ \\ 1 Department of Electrical, Automation and Electronic Engineering and Applied Physic ETSIDI Technical \\ University of Madrid, 28012 Madrid, Spain \\ 2 Department of Electrical Engineering Carlos III University of Madrid, 28911 Madrid, Spain; \\ danserra@ing.uc3m.es (D.S.-J.); jsanz@ing.uc3m.es (J.S.) \\ 3 Electrical and Computer Engineering Department and Mechanical Engineering-Engineering Mechanics \\ Department Michigan Technological University, Houghton, MI 49931, USA; gauchia@mtu.edu \\ * Correspondence: sp.castano@upm.com; Tel.: +34-91336-6858
}

Academic Editor: Rodolfo Araneo

Received: 3 January 2017; Accepted: 22 February 2017; Published: 25 February 2017

\begin{abstract}
This work analyzes the effects of a BMS (battery management system) on the characterization and modeling of series and parallel connections of Li-ion cell packs. The Li-ion pack studied consists of four series modules connected in parallel. This pack has been characterized by means of charge, discharge and frequency tests. As a result of these tests, series and parallel influence on battery parameters have been determined. A model considering the effects of a BMS is established and compared with a model based on a single-cell approach. Experimental validations show that the single cell based approach gives poor results in comparison with a model that considers BMS effects.
\end{abstract}

Keywords: Li-ion pack; battery management system (BMS) effect; modeling; testing; hardware-in-the-loop (HIL) simulation

\section{Introduction}

Since rechargeable Li-ion batteries appeared commercially in the 1990s, this technology has experienced impressive growth, initially as an energy source for portable electronic devices (MP3, cameras, power tools, etc.) [1] and then as the main power source in electrified transportation. Now, batteries are becoming a key element for developing smart grids [2,3]. In comparison to other technologies such as $\mathrm{Pb}$-acid or $\mathrm{NiMH}$, Li-ion batteries are the most promising technology for storing energy due to their high specific energy, specific power and long shelf life [4,5]. Even though Li-ion cells have rated voltages $(4 \mathrm{~V})$ greater than $\mathrm{Pb}$-acid or NiMH cells, it is necessary in medium- and high-power applications, connecting the cells in series and parallel to obtain the required output voltage and/or current.

Li-ion cells may have slightly different internal parameters (capacity, resistance, etc.). This is mainly due to the manufacturing process, but also to different ageing process evolution (calendar and cycle ageing) and environmental conditions that can affect the evolution of cell parameters during normal operation [6,7]. This situation means that the overall voltage may not be uniformly distributed over the different cells of the string (in the case of serial connections), as is desirable. For this reason a battery management system (BMS) is used to equalize the cell voltages within a series string and the string current between parallel paths, thus protecting the battery module from undervoltage/overvoltage, short-circuit and thermal runway [8]. To guarantee a safe module performance, the BMS is in charge of measuring the cell voltage, module current, and temperature and controlling pack charging and discharging processes. To carry out these functions, BMSs are composed of sensors, actuators, regulators, and electronic devices among others [6]. All of these elements interact 
with the cells to improve the pack performance. However, this effect is rarely considered in traditional Li-ion pack models found in the scientific literature [9-11].

Therefore, battery modules based on Li technologies should be modeled taking into account the BMS's effect on module performance. However, the usual modelling procedure is to consider an aggregate model of single cells, which is valid for battery technologies such as $\mathrm{Pb}$ or $\mathrm{Ni}$, neglecting BMS effects on the module operation. In this work, the study started in [12] is expanded with the analysis of BMS effects on series and parallel connections performance. For this purpose, a battery pack consisting of a parallel connection of several series-connected strings has been tested and modeled. In order to determine which simulation approach gives the best results, a comparison of model responses based on a single cell and BMS effects has been performed. Modeling results have been experimentally validated by means of hardware-in-the-loop (HIL) tests that reproduce real battery operating conditions.

The content of this paper is organized as follows. In Section 2 the experimental analysis is explained. In Section 3 battery pack models are defined and experimentally compared with the real battery module by means of hardware-in-the-loop (HIL) simulation. Finally, Section 4 presents the conclusions.

\section{Experimental Analysis}

The effect of BMS in series and parallel connections has been studied in a commercial battery pack composed of four parallel-connected strings, each one composed of a series of seven cells. Its rated values are $25.0 \mathrm{~V}$ rated voltage, $50 \mathrm{Ah}$ rated capacity and a maximum voltage of $29.4 \mathrm{~V}$. Figure 1 shows a schematic representation of the pack connections. As can be seen, each string is separately controlled by means of a management system which measures cell voltage, string temperature and string current, also this system controls cell balancing, cell overvoltage and cell undervoltage. The overall pack management system controls the performance of the whole pack, evaluating the measurements of the series management systems and controlling the pack charging and discharging processes.

The most common approach for battery modeling in electrical applications is based on an equivalent electrical circuit [13-15]. In this circuit a voltage source simulates the active behavior of the battery and the electrical elements the passive one (impedance), as shown in Figure 2. The response of the voltage source that includes the relationship between the open circuit voltage (OCV) and the state of charge (SOC) is determined by pulsed charge and discharge tests $[6,16]$. Battery impedance can be accurately calculated by means electrochemical impedance spectroscopy (EIS) tests [17]. In order to determine the BMS effects in pack modeling, the experimental results of charge, discharge and EIS test of series and parallel connections are analyzed as explained following. All these tests have been carried out on the battery pack described above using the experimental setup shown in Figure 3.

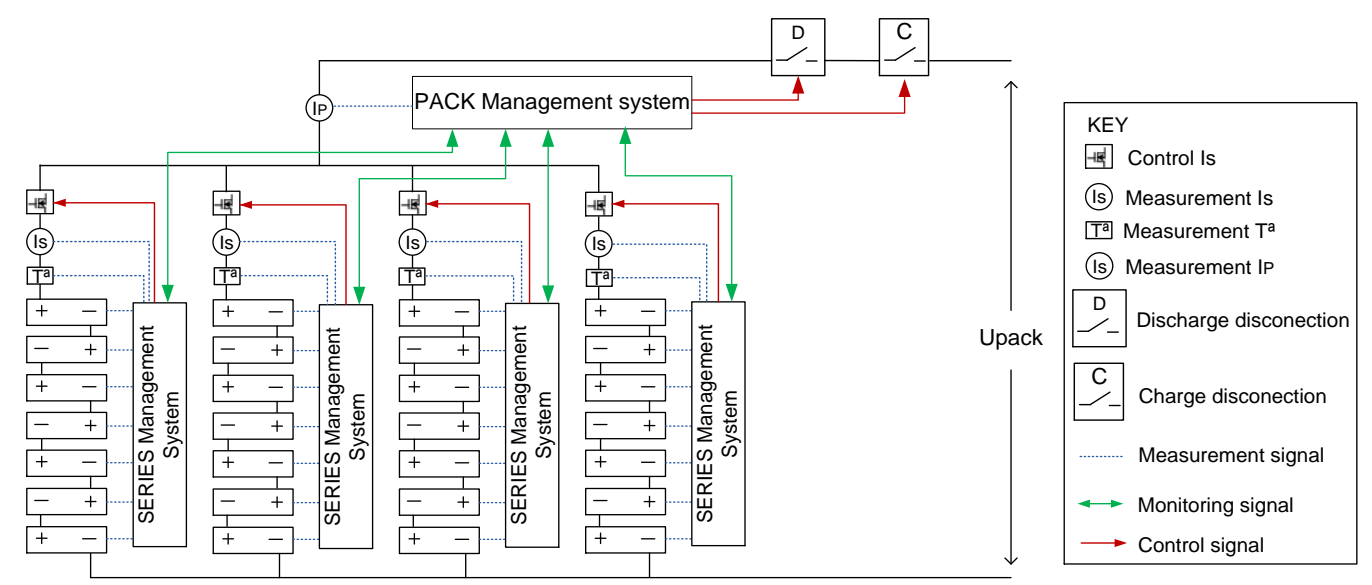

Figure 1. Li-ion pack layout. 


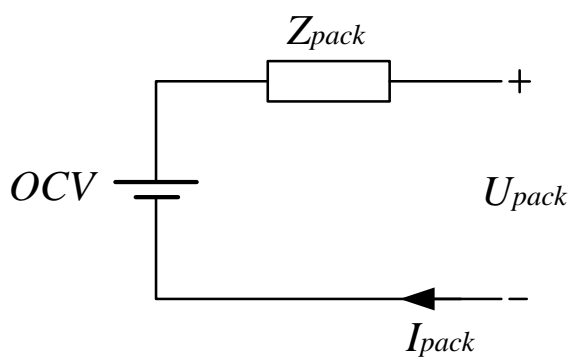

Figure 2. Battery electrical circuit.

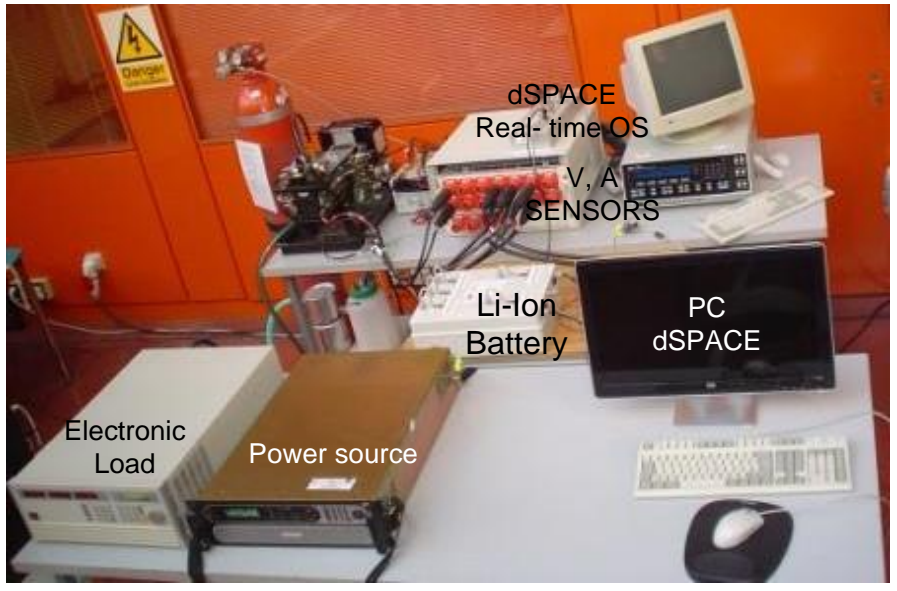

Figure 3. Picture of the experimental setup.

\subsection{Series Analysis}

The effect of the BMS on the characterization of the pack series connections are analyzed by comparing the results of experimental measurements of charge and discharge and EIS tests to the results calculated based on a single cell approach.

\subsubsection{BMS Effects on Power Source}

The experiment to determine the SOC-OCV relationship starts with the battery module totally charged (CC/CV charging method, at $I=25 \mathrm{~A})$. After that, the battery pack is discharged with current pulses of 10 A during $30 \mathrm{~min}$ followed by $90 \mathrm{~min}$ of relaxation time. The OCV is measured in the pack terminals and in each series connection when the relaxation period ends. After the discharge test, the battery is recharged by means of current pulses of $10 \mathrm{~A}$ for $30 \mathrm{~min}$ followed also by a $90 \mathrm{~min}$ relaxation period. As in the case of discharge test, the OCV is measured in the pack terminals and in each series connection when the relaxation time ends. In the case of a single cell, the discharge tests are carried out from $100 \%$ to $0 \%$ because the cell is not protected by a BMS [18,19]. However, in a battery pack the cells are controlled by a BMS that limits the minimum cell SOC to $20 \%$ to prevent cell under-voltages. In the same way, the current pulses during the charge process are limited when the pack voltage reaches $29.4 \mathrm{~V}$. The results of charge and discharge tests of the battery pack are shown in Figure 4. 


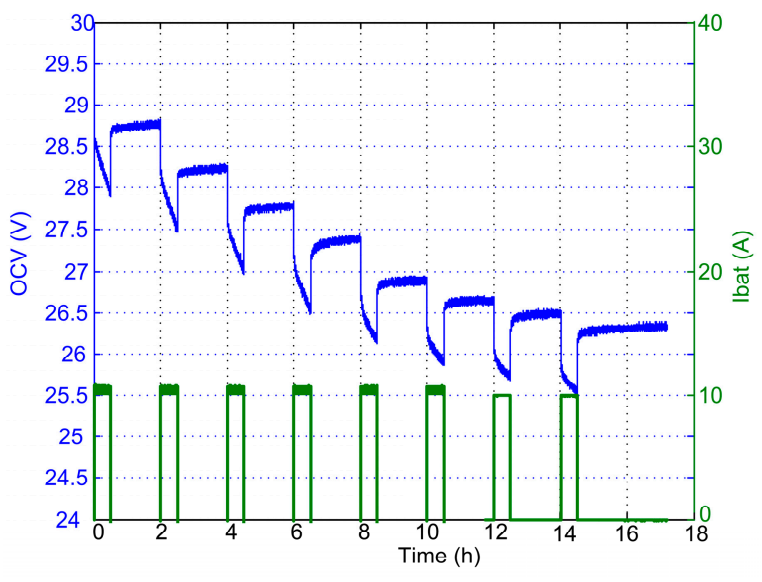

(a)

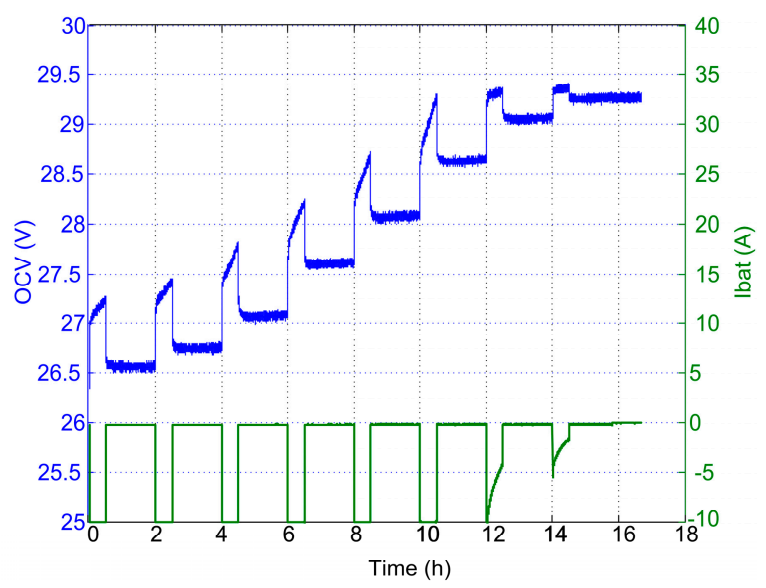

(b)

Figure 4. (a) Discharge and (b) charge tests results.

In Figure 5 the comparison of the OCV-SOC characteristics of each series connection based on the single cell approach and the BMS approach are shown. As can be seen, the shape of the OCV vs. SOC curve of each series connection is different from the curve based on single cell measurements because of the BMS effects. The deviation of OCV estimation is bigger than $0.76 \mathrm{~V}$ for SOCs under $60 \%$. For SOCs greater than $60 \%$ this deviation is lower, but the single cell approach does not reproduce the OCV-SOC relationship of the series connections analyzed.

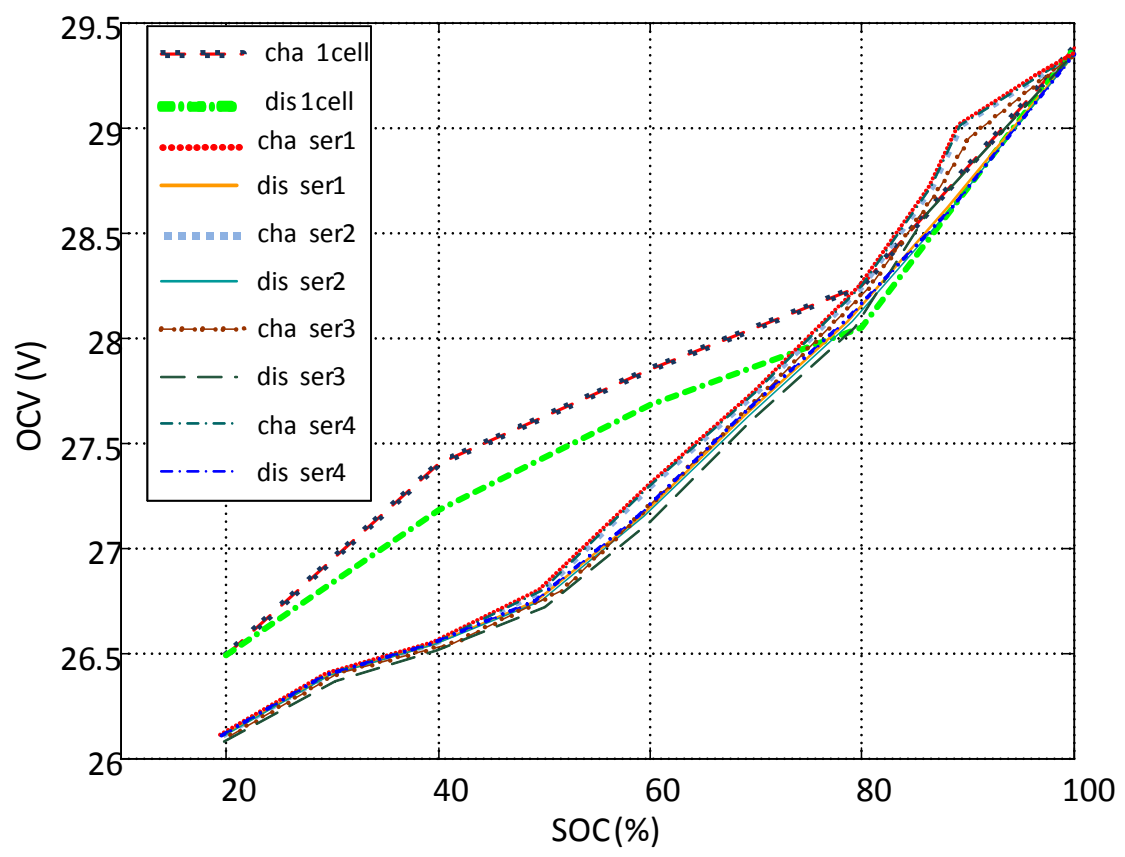

Figure 5. OCV vs. SOC curves comparison.

\subsubsection{BMS Effects on Impedance Parameters}

Electrochemical impedance spectroscopy (EIS) is a well-proven and very accurate experimental technique used to determine the complex impedance of electrochemical systems, such as fuel cells (FC) [20], batteries [21] or supercapacitors (SC) [22]. Unlike impedance modeling techniques in the time domain, EIS tests allow us to easily fit an equivalent circuit model, which is very useful for modeling the electrical parameters of an energy system. To carry out EIS tests a low amplitude ac 
ripple command signal of variable frequency is applied. If the input signal is current, it is said to be a galvanostatic mode EIS test, whilst if it is a voltage signal it is called a potentiostatic mode. This input signal produces an output signal (current or voltage). The impedance is calculated by dividing voltage and current at each test frequency. In this work current-controlled (galvanostatic) EIS tests have been carried out. In order to study the influence of SOC variations in impedance parameters, EIS tests are realized at $20 \%, 40 \%, 60 \%$, and $80 \%$ SOC. The effects of the BMS in impedance modeling have been determined comparing experimental results of single cells and the series connections of the tested pack.

Figures 6 and 7 show the EIS tests results of the single cells and the four series connections of the battery pack. Because the EIS responses of cells are very similar, only one representative cell of each string has been presented in Figure 6. The Nyquist plots show that the impedances of single cells and the series connection have similar behavior and reveal the SOC dependence of impedance parameters in the frequency range from $1 \mathrm{mHz}$ to $7.5 \mathrm{~Hz}$. At very low frequencies (from $1 \mathrm{mHz}$ to $53 \mathrm{mHz}$ ) both real $\left(Z^{\prime}\right)$ and imaginary $\left(Z^{\prime \prime}\right)$ impedances decrease with frequency. This phenomenon corresponds with the diffusion process in a porous electrode, and it is represented by a $45^{\circ}$ slope in the Nyquist plot. During the low frequency range $(10 \mathrm{mHz}-4 \mathrm{~Hz})$ Nyquist plots present a capacitive semi-circle that grows with decreasing state of charge (SOC). From medium frequencies $(7.5 \mathrm{~Hz})$ to the resonance frequency, fresh, the impedance behavior is represented by a capacitive semi-circle that remains almost constant to changes in SOC. The equivalent serial resistance also remains constant to changes in SOC. Beyond fres $\mathrm{Hz}$, the Nyquist plots show an inductive behavior.

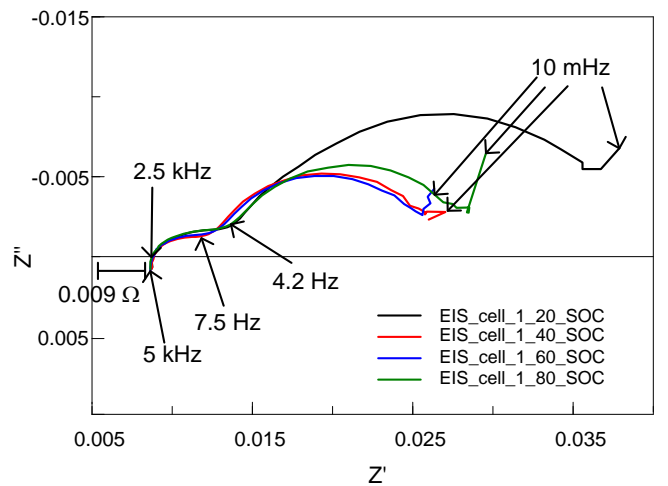

Single cell series 1

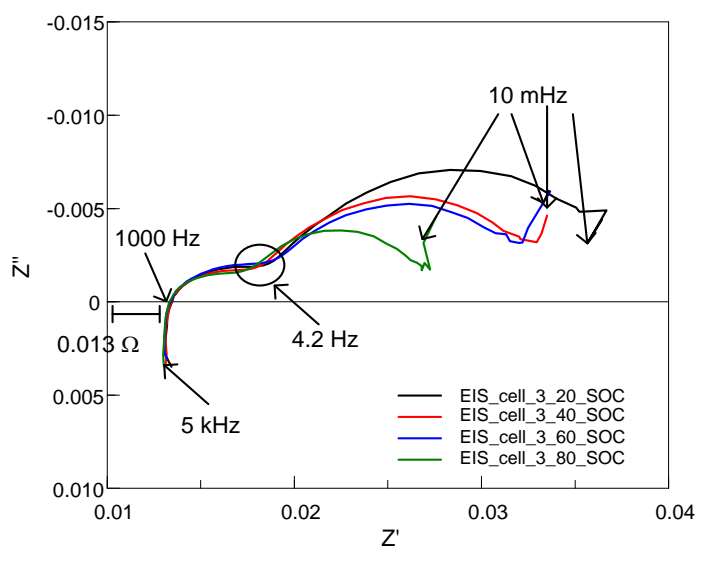

Single cell series 3

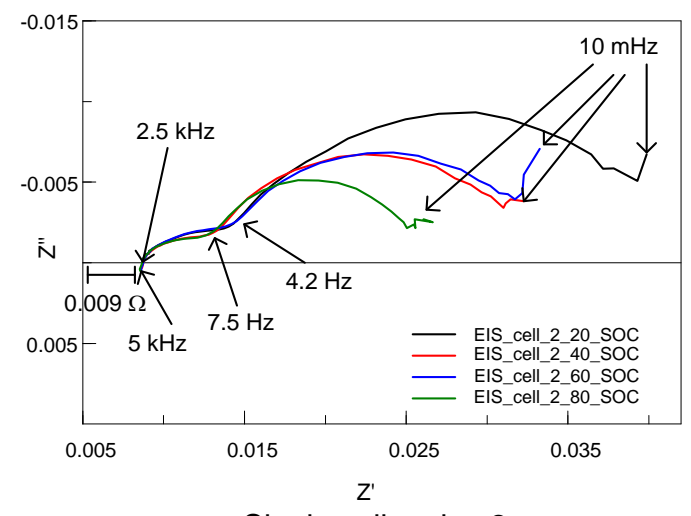

Single cell series 2

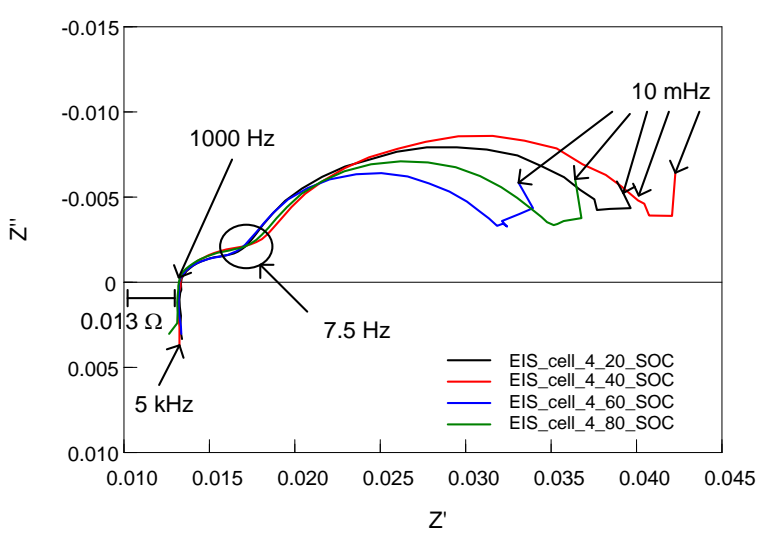

Single cell series 4

Figure 6. Cell electrochemical impedance spectroscopy (EIS) results. 


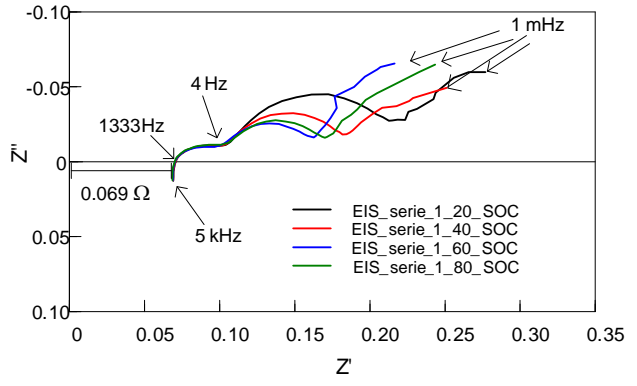

Series 1

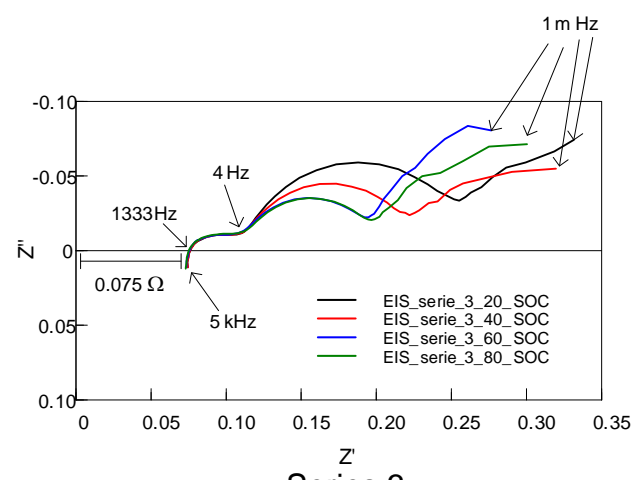

Series 3

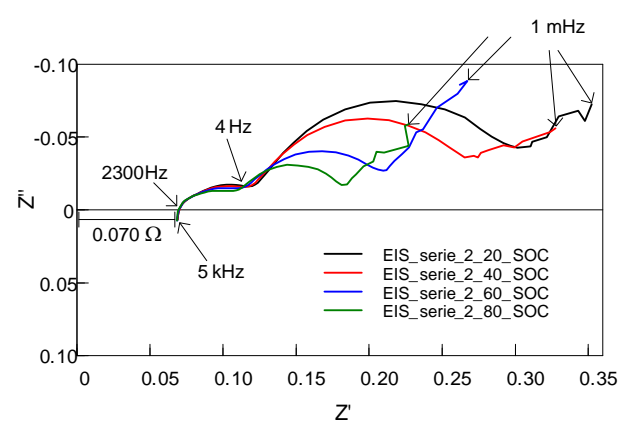

Series 2

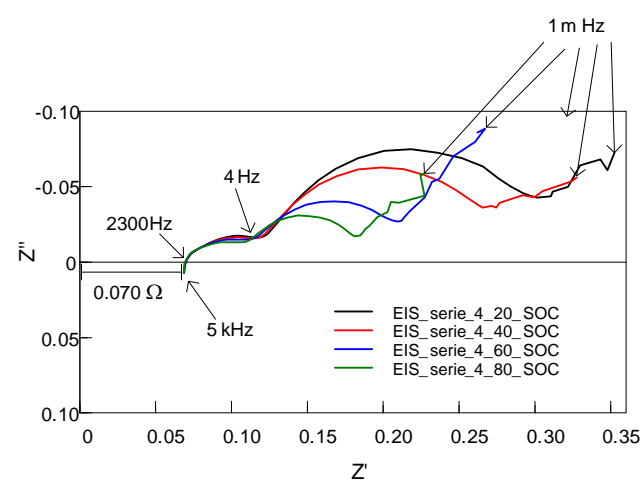

Series 4

Figure 7. Series connections EIS results.

From these experimental results, the parameters of the equivalent impedance can be calculated. To do so, the electrical circuit tool included in the Zview ${ }^{\circledR}$ software (3.1, Ameteck, Leicester, UK) has been used. This function allows comparing the results of the Nyquist plot with an electrical circuit defined by the user. In this way the electrical parameters of the tested battery pack have been fitted. Because most of the electrical applications do not operate at high frequencies, the inductive behavior has been neglected. In this work the capacitive behavior is simulated by means of RC parallel networks in series with a resistance (Ro) that represents the ohmic resistance of the device. In order to determine the differences between single cells and series connections (seven cells) impedance in Tables 1 and 2 the numerical values of the impedance parameters are shown. Due to EIS results presenting a similar behavior, average values of the parameters are used. In Table 3 the impedance of the average series connection based on single cell values is calculated.

Table 1. Cell impedance parameters.

\begin{tabular}{ccccc}
\hline Parameter & $\mathbf{2 0} \%$ SOC & $\mathbf{4 0} \%$ SOC & $\mathbf{6 0 \%}$ SOC & $\mathbf{8 0 \%}$ SOC \\
\hline Ro & 0.012 & 0.012 & 0.012 & 0.012 \\
$\tau 1(\mathrm{R} 1 / / \mathrm{C} 1)$ & 15.26 & 12.39 & 10.21 & 7.61 \\
$\tau 2(\mathrm{R} 2 / / \mathrm{C} 2)$ & 0.186 & 0.118 & 0.086 & 0.075 \\
$\tau 3(\mathrm{R} 3 / / \mathrm{C} 3)$ & 0.00151 & 0.00149 & 0.00151 & 0.00150 \\
\hline
\end{tabular}

Table 2. Series connections impedance parameters.

\begin{tabular}{ccccc}
\hline Parameter & $\mathbf{2 0} \%$ SOC & $\mathbf{4 0 \%}$ SOC & $\mathbf{6 0 \%}$ SOC & $\mathbf{8 0} \%$ SOC \\
\hline Ro & 0.071 & 0.071 & 0.071 & 0.071 \\
$\tau 1(\mathrm{R} 1 / / \mathrm{C} 1)$ & 93.27 & 73.52 & 62.65 & 45.28 \\
$\tau 2(\mathrm{R} 2 / / \mathrm{C} 2)$ & 1.103 & 0.716 & 0.511 & 0.458 \\
$\tau 3(\mathrm{R} 3 / / \mathrm{C} 3)$ & 0.0096 & 0.0094 & 0.0095 & 0.0093 \\
\hline
\end{tabular}


Table 3. Series connections impedance parameters calculated from single cell values.

\begin{tabular}{ccccc}
\hline Parameter & $\mathbf{2 0} \%$ SOC & $\mathbf{4 0} \%$ SOC & $\mathbf{6 0} \%$ SOC & $\mathbf{8 0} \%$ SOC \\
\hline Ro & 0.084 & 0.084 & 0.084 & 0.084 \\
$\tau 1(\mathrm{R} 1 / / \mathrm{C} 1)$ & 106.82 & 86.72 & 71.47 & 53.27 \\
$\tau 2(\mathrm{R} 2 / / \mathrm{C} 2)$ & 1.302 & 0.823 & 0.601 & 0.524 \\
$\tau 3(\mathrm{R} 3 / / \mathrm{C} 3)$ & 0.0106 & 0.0104 & 0.0106 & 0.0105 \\
\hline
\end{tabular}

Impedance parameters results confirm the influence of BMS on the series connection behavior. The values presented in the above tables show significant differences between impedance parameters when they are calculated based on single cell measurements and series connections measurements. Table 4 shows the errors between impedance parameters of the series connections calculated using single cell approach (data presented in Table 2) and the series connections measurements (data presented in Table 3). Ro present the biggest difference (deviations up 18\%). The rest of parameters $(\tau 1, \tau 2, \tau 3)$ calculated from single cell approach present errors greater than $10 \%$ of the actual values. As in the case of power source analysis, BMS effects can be observed in impedance parameters.

Table 4. Errors of impedance parameters calculated by single cell approach.

\begin{tabular}{ccccc}
\hline \multirow{2}{*}{ Parameter } & $\begin{array}{c}\mathbf{2 0 \%} \text { SOC } \\
\text { Error (\%) }\end{array}$ & $\begin{array}{c}\mathbf{4 0 \%} \text { SOC } \\
\text { Error (\%) }\end{array}$ & $\begin{array}{c}\mathbf{6 0 \%} \text { SOC } \\
\text { Error (\%) }\end{array}$ & $\begin{array}{c}\mathbf{8 0 \% ~ S O C} \\
\text { Error (\%) }\end{array}$ \\
\hline Ro & -18.31 & -18.31 & -18.31 & -18.31 \\
$\tau 1(\mathrm{R} 1 / / \mathrm{C} 1)$ & -14.53 & -17.95 & -14.08 & -17.65 \\
$\tau 2(\mathrm{R} 2 / / \mathrm{C} 2)$ & -18.04 & -14.94 & -17.61 & -14.41 \\
$\tau 3(\mathrm{R} 3 / / \mathrm{C} 3)$ & -10.42 & -10.64 & -11.58 & -12.90 \\
\hline
\end{tabular}

\subsection{Parallel Analysis}

As in the case of series analysis, charge, discharge and EIS tests results of the parallel connection are compared with the results based on the parallel aggregation of single cells to determine BMS influence in battery pack parameters.

\subsubsection{BMS Effects on Power Source}

Figure 8 shows the comparison of OCV-SOC characteristics of parallel connection (pack terminals) and single cell approach. As can be seen the OCV-SOC curve based on single cell approach is not able to reproduce the parallel connection behavior, as in the case of series analysis. The maximum deviation of OCV estimation is almost $0.8 \mathrm{~V}$ for SOCs under $60 \%$.

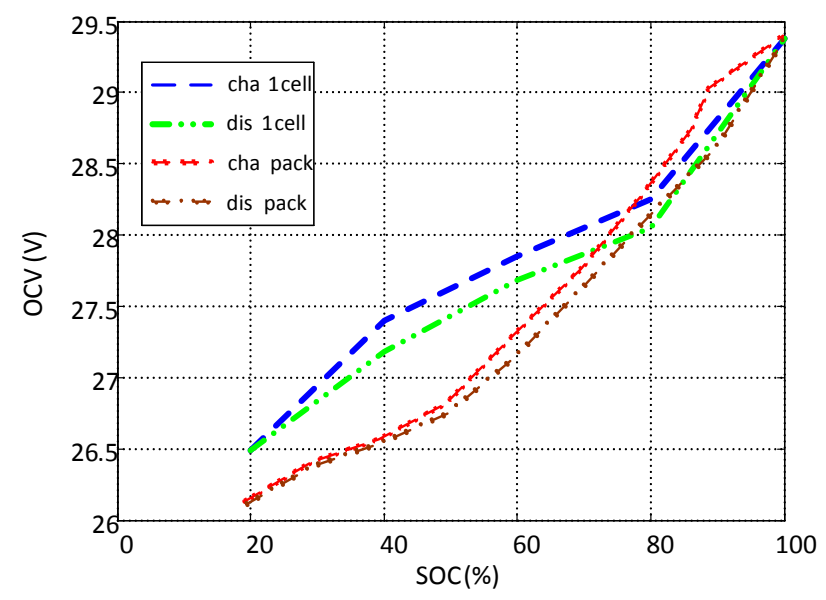

Figure 8. OCV vs. SOC curves comparison. 


\subsubsection{BMS Effects on Impedance Parameters}

Figure 9 shows the EIS results of the parallel connection. The impedance parameters of the parallel connections are calculated following the procedure explained in the series analysis. The results are displayed in Table 5. Table 6 shows the impedance parameters of the parallel connection calculated by the single cell approach. The comparison between experimental parameters and single cell approach shows that Ro present the maximum difference (deviations up $46 \%$ ) and $\tau 3$ the minimum one $(7 \%)$, as it is shown in Table 7. EIS tests results depict that impedance model based on single cell approach fails to reproduce the impedance behavior of the parallel connection.

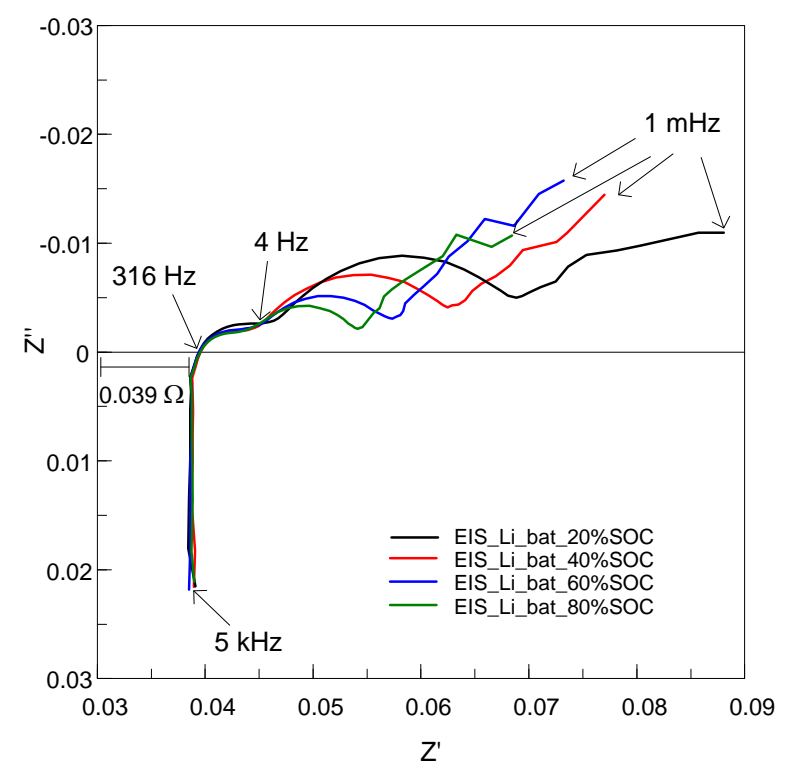

Figure 9. Parallel connection EIS results.

Table 5. Parallel connection impedance parameters.

\begin{tabular}{ccccc}
\hline Parameter & $\mathbf{2 0} \%$ SOC & $\mathbf{4 0} \%$ SOC & $\mathbf{6 0} \%$ SOC & $\mathbf{8 0} \%$ SOC \\
\hline Ro & 0.039 & 0.039 & 0.039 & 0.039 \\
$\tau 1(\mathrm{R} 1 / / \mathrm{C} 1)$ & 23.40 & 18.43 & 15.71 & 11.39 \\
$\tau 2(\mathrm{R} 2 / / \mathrm{C} 2)$ & 0.295 & 0.188 & 0.136 & 0.116 \\
$\tau 3(\mathrm{R} 3 / / \mathrm{C} 3)$ & 0.0028 & 0.0030 & 0.0030 & 0.0029 \\
\hline
\end{tabular}

Table 6. Parallel connection impedance parameters calculated from single cell values.

\begin{tabular}{ccccc}
\hline Parameter & $\mathbf{2 0} \%$ SOC & $\mathbf{4 0} \%$ SOC & $\mathbf{6 0} \%$ SOC & $\mathbf{8 0} \%$ SOC \\
\hline Ro & 0.021 & 0.021 & 0.021 & 0.021 \\
$\tau 1(\mathrm{R} 1 / / \mathrm{C} 1)$ & 26.70 & 21.68 & 17.87 & 13.32 \\
$\tau 2(\mathrm{R} 2 / / \mathrm{C} 2)$ & 0.326 & 0.206 & 0.150 & 0.131 \\
$\tau 3(\mathrm{R} 3 / / \mathrm{C} 3)$ & 0.0026 & 0.0027 & 0.0027 & 0.0026 \\
\hline
\end{tabular}

Table 7. Errors of impedance parameters calculated by single cell approach.

\begin{tabular}{|c|c|c|c|c|}
\hline Parameter & $\begin{array}{c}20 \% \text { SOC } \\
\text { Error (\%) }\end{array}$ & $\begin{array}{c}40 \% \text { SOC } \\
\text { Error (\%) }\end{array}$ & $\begin{array}{l}60 \% \text { SOC } \\
\text { Error (\%) }\end{array}$ & $\begin{array}{l}80 \% \text { SOC } \\
\text { Error (\%) }\end{array}$ \\
\hline Ro & 46.15 & 46.15 & 46.15 & 46.15 \\
\hline$\tau 1(\mathrm{R} 1 / / \mathrm{C} 1)$ & -14.12 & -17.63 & -13.73 & -16.92 \\
\hline$\tau 2(\mathrm{R} 2 / / \mathrm{C} 2)$ & -10.34 & -9.44 & -10.48 & -12.93 \\
\hline$\tau 3(\mathrm{R} 3 / / \mathrm{C} 3)$ & 7.14 & 10.00 & 11.67 & 9.48 \\
\hline
\end{tabular}




\section{Battery Pack Modeling Approach Comparison}

\subsection{Battery Pack Models}

Figure 10 presents the electric circuit used to simulate the behavior of the tested battery pack. Two models have been evaluated and compared. The model of the battery pack that considers the BMS effects is calculated from EIS tests results presented in Table 5. The other model corresponds to the mere aggregation of single cell responses, whose parameters have been calculated using the data presented in Table 6. For both models the battery pack voltage upack is described by Equation (1).

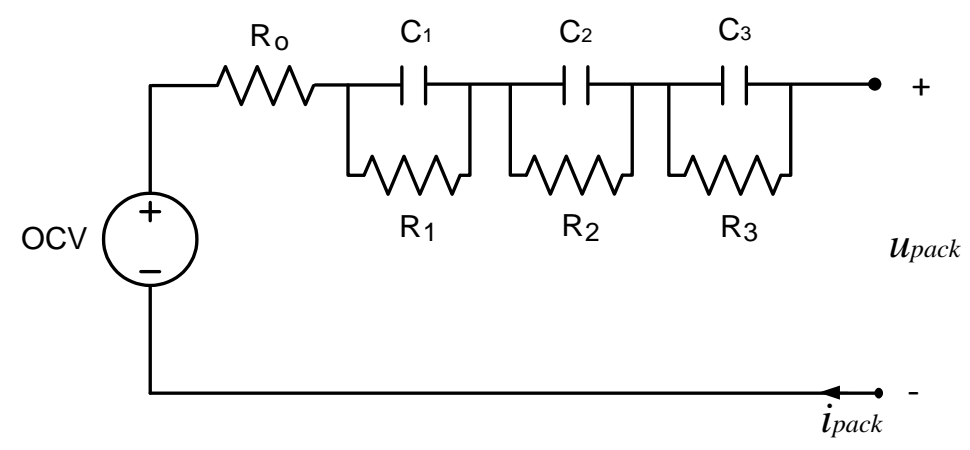

Figure 10. Battery pack electric circuit.

$$
u_{\text {pack }}=O C V-u_{R o}-u_{C 1}-u_{C 2}-u_{C 3}
$$

where:

$$
\begin{gathered}
u_{R o}=R_{o} \cdot i_{b a t} \\
u_{C 1}=\int \frac{1}{C_{1}} \cdot\left(i_{b a t}-\frac{u_{C 1}}{R_{C 1}}\right) \cdot d t \\
u_{C 2}=\int \frac{1}{C_{2}} \cdot\left(i_{b a t}-\frac{u_{C 2}}{R_{C 2}}\right) \cdot d t \\
u_{C 3}=\int \frac{1}{C_{3}} \cdot\left(i_{b a t}-\frac{u_{C 3}}{R_{C 3}}\right) \cdot d t
\end{gathered}
$$

\subsection{Battery Pack Model Validation}

In order to determine which model has better accuracy, the experimental voltage at battery pack terminals has been compared with the voltage response of the models calculated above. This experimental comparison has been performed using a hardware-in-the-loop (HIL) simulation that represents the battery power demanded by an electric vehicle. HIL simulation is extensively used to test electric and mechanic systems because real devices are replaced by their models and lab equipment can be used [23-25].

The HIL simulation used in this work is composed of both a software and a hardware simulation of the EV, as shown in Figure 11. The electrical model used in the software simulation is based on the model proposed by [26], which reproduces the behavior of an electric vehicle with an equivalent mass of $1000 \mathrm{~kg}$, frontal area of $2 \mathrm{~m}^{2}$, drag coefficient of 0.35 , and includes the electric drive, gear box, differential, wheels and environmental resistive forces and the vehicle speed and current control loops. In this experimental setup $1 \mathrm{~W}$ simulated corresponds to $25 \mathrm{~W}$ in the real electric vehicle. The EV hardware simulation is realized by means of an electronic load and a power source, which are controlled in synchronization to simulate the vehicle power demand during acceleration (discharge process) and regenerative braking (charge process). 


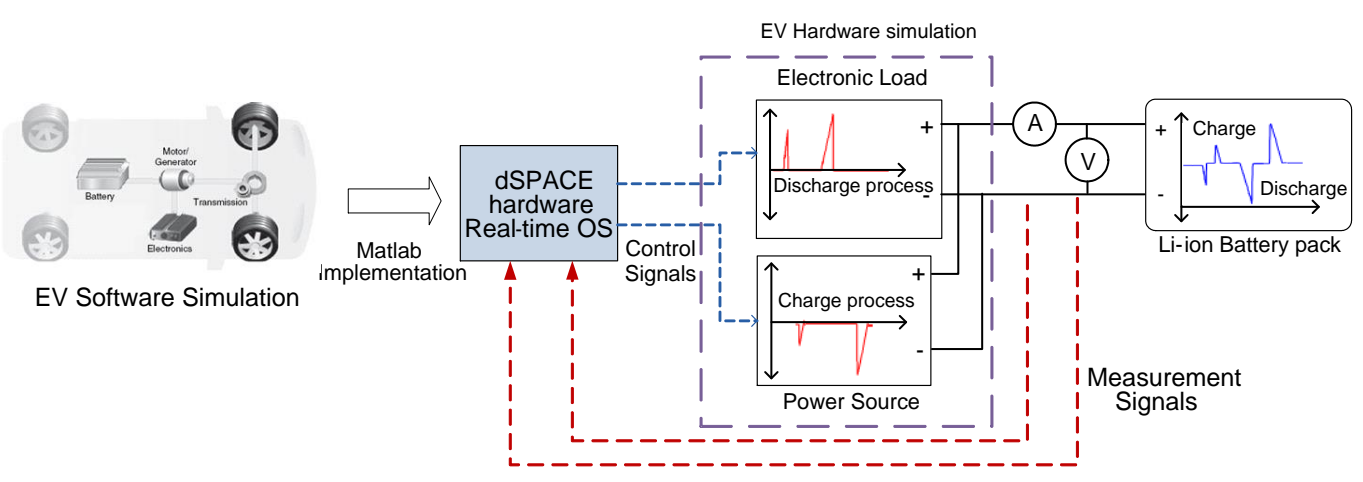

Figure 11. EV HIL simulation.

Both the vehicle HIL and the battery pack are controlled in real-time by the dSpace ${ }^{\circledR}$ control system (PX10, dSpace, Wixom, MI, USA). To do so, the EV power demand is calculated according to the speed of the driving cycle. Knowing that the real battery pack imposes its voltage to the simulated HIL vehicle, the electronic load and power source are externally programmed to supply/absorb the power demanded through external control signals. As a result of HIL simulation current and voltage profiles of the battery pack are generated.

The driving cycles analyzed represent normalized and real-world conditions. In this way, the battery behavior at acceleration, deceleration and deep discharge are studied. The Normalized New European Driving Cycle (NEDC) simulates both urban and highway driving conditions. The urban part is formed by four stages of acceleration and deceleration to full stops. The maximum speed is $50 \mathrm{~km} / \mathrm{h}$ for urban routes and $120 \mathrm{~km} / \mathrm{h}$ for highway, the total time is $1180 \mathrm{~s}$, the average speed is $42 \mathrm{~km} / \mathrm{h}$, and the total distance is approximately $11,000 \mathrm{~m}$. The New York City cycle (NYCC) reproduces a driving route in New York City with during $598 \mathrm{~s}$, a total distance of $1902.8 \mathrm{~m}$ and average speed of $11.5 \mathrm{~km} / \mathrm{h}$. In Figure 12 the driving cycles are shown. Figure 13 shows the power profiles determined by the simulation of the driving cycles.

The current profiles of the battery pack generated by HIL simulation (Figure 14) have been used as input of the battery models (Figure 10) implemented in Matlab/Simulink ${ }^{\circledR}$ (2010, Mathworks, Natick, MA, USA). Figure 15 shows the comparison between the voltage measured at pack terminals (Up exp) and simulated battery pack voltages. As can be seen, the model considering the influence of BMS on pack performance (Up BMS) shows a higher degree of accuracy than the model based on single cell approach (Up 1 cell). Maximum errors are less than $0.7 \%$ at NEDC and less than $0.5 \%$ at NYCC for the model that consider BMS effects, whilst maximum errors for the single cell-based model are almost $5 \%$ for both cycles.

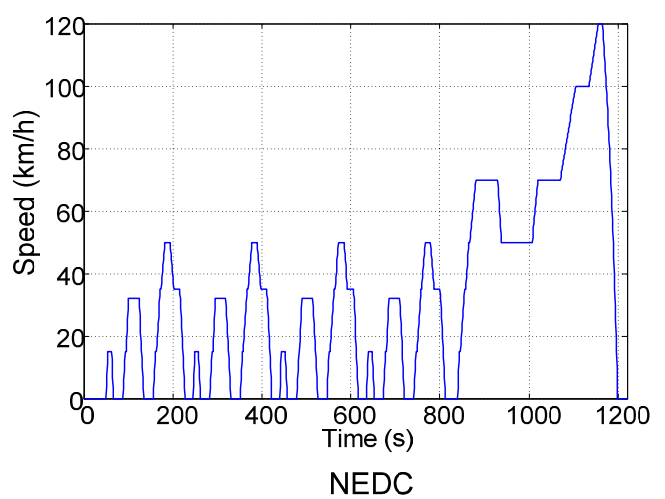

(a)

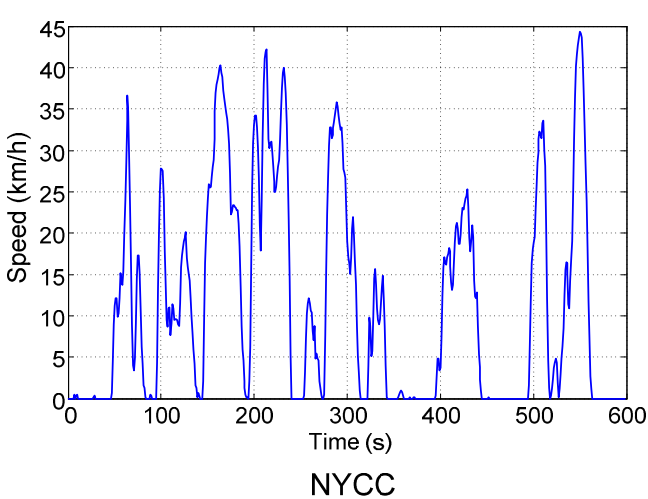

(b)

Figure 12. (a) Normalized New European Driving Cycle (NEDC) and (b) NYCC driving cycles. 


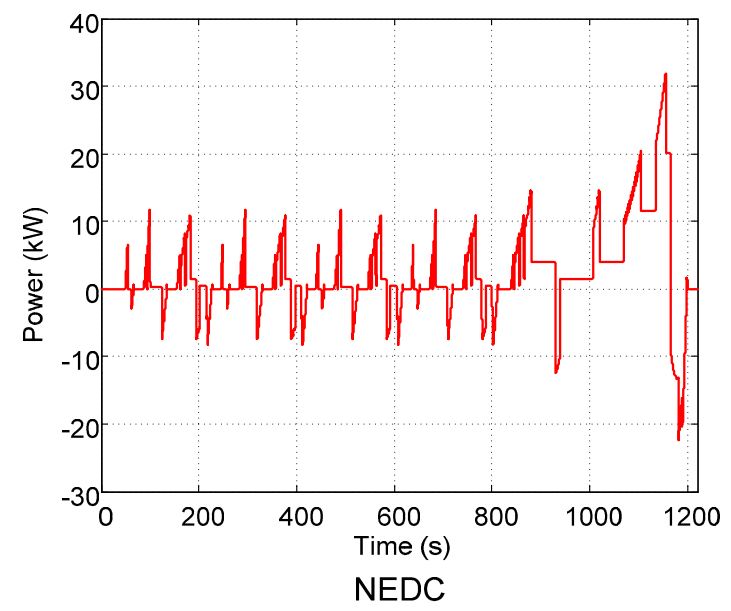

(a)

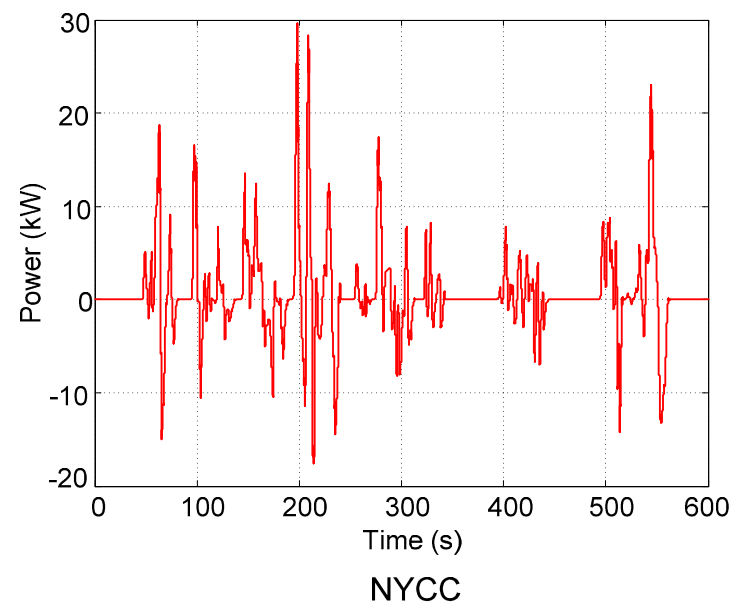

(b)

Figure 13. Power at (a) NEDC and (b) NYCC driving cycles.
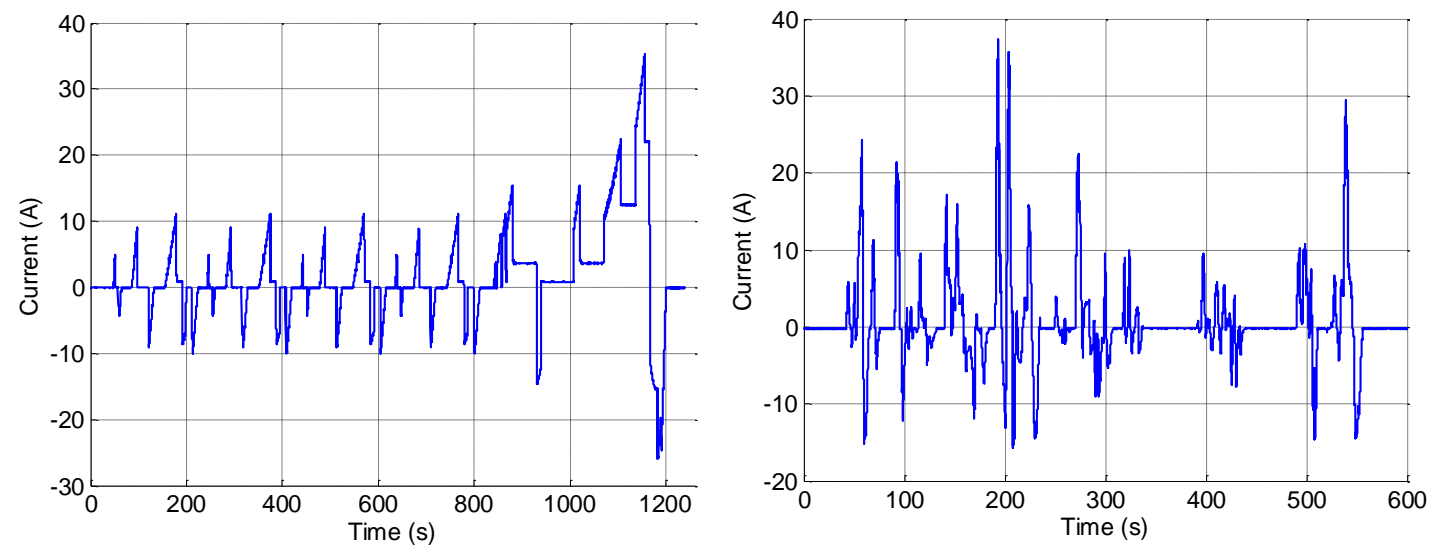

Figure 14. Battery current profiles.
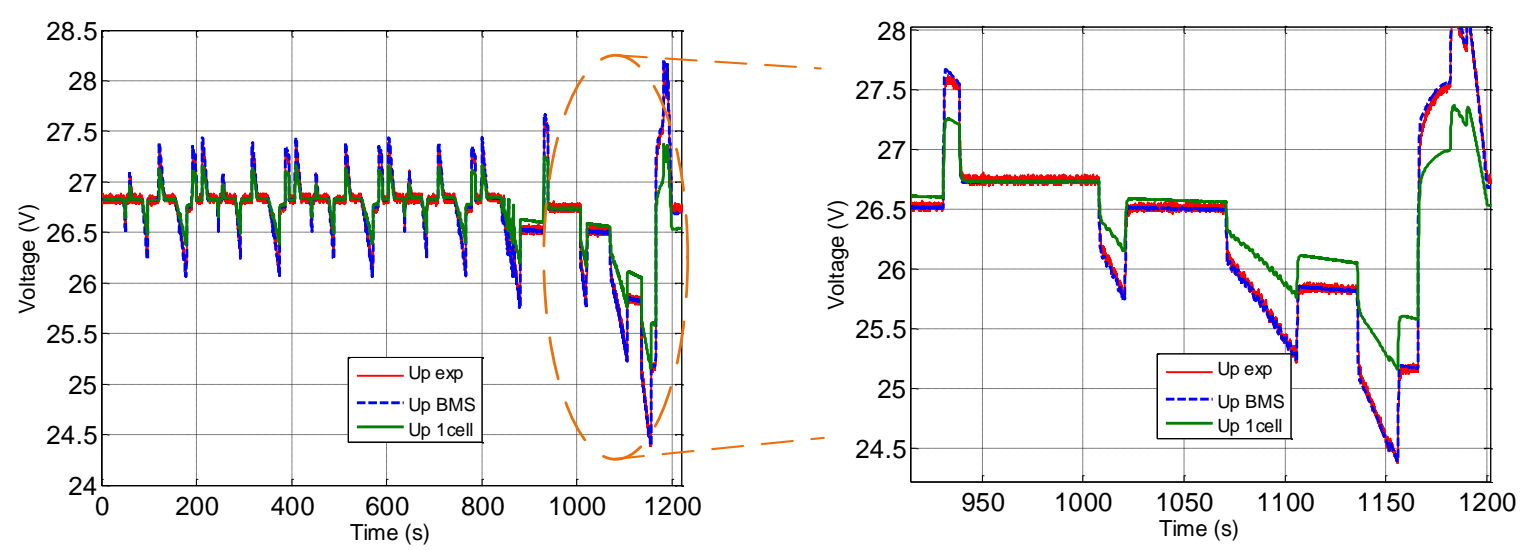

NEDC

Figure 15. Cont. 

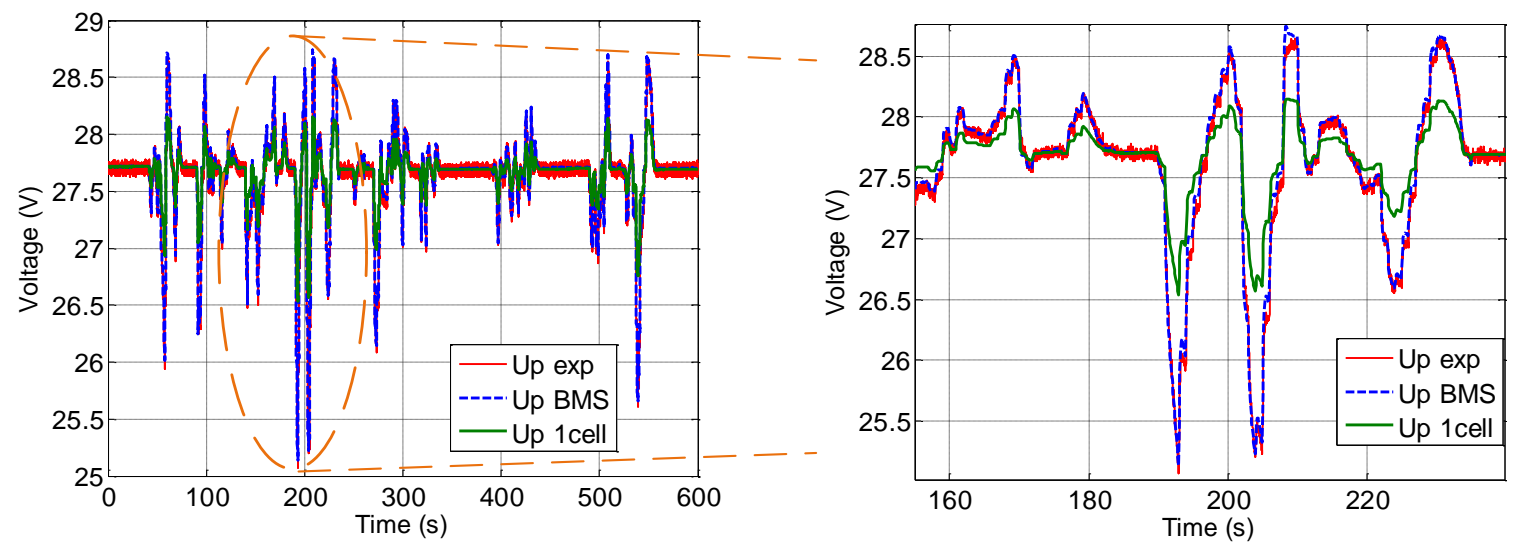

NYCC

Figure 15. Battery experimental vs. simulated voltages.

\section{Conclusions}

In this work BMS effects on characterization and modeling of series and parallel Li-ion cells connections was analyzed by means of charge, discharge and EIS tests. To do so, a commercial battery pack of four parallel-connected strings, each one composed of a series of seven cells Li-ion, has been analyzed. According to the experimental results BMS effects can be observed in the parameters of the power supply and impedance of series and parallel connections of Li-ion cells.

A battery pack model that considers BMS effects has been established. Also, a battery pack based on a single cell approach has been calculated. In order to determine which model can reproduce the pack behavior, an HIL simulation of an electric vehicle has been carried out. Experimental validation shows that the model which considers BMS effects has a higher degree of accuracy than the model based on a single cell approach. These results proved that the single cell approach fails to model series and parallel connections of Li-ion cells. Thus, we can conclude that considering BMS effects on module performance improves modeling reliability (Maximum errors less than $0.7 \%$ ). Therefore, BMS effects on Li-ion battery pack performance, regardless of the number of series or parallel cells, should always be taken into account whenever a high degree of accuracy is required.

Author Contributions: All authors planned the study; Sandra Castano-Solis performed the experiments; Sandra Castano-Solis and Daniel Serrano-Jimenez analyzed the data and wrote the paper; Lucia Gauchia and Javier Sanz contributed to the discussion and provided guidance throughout the work.

Conflicts of Interest: All authors declare that there is no conflict of interests regarding the publication of this paper.

\section{References}

1. Dubarry, M.; Liaw, B.Y. Development of a universal modeling tool for rechargeable lithium batteries. J. Power Sources 2007, 174, 856-860. [CrossRef]

2. Khaligh, A.; Li, Z. Battery, ultracapacitor, fuel cell, and hybrid energy storage systems for electric, hybrid electric, fuel cell, and plug-in hybrid electric vehicles: State of the art. IEEE Trans. Veh. Technol. 2010, 59, 2806-2814. [CrossRef]

3. Scrosati, B.; Garche, J. Lithium batteries: Status, prospects and future. J. Power Sources 2010, 195, 2419-2430. [CrossRef]

4. Lukic, S.M.; Cao, J.; Bansal, R.C.; Rodriguez, F.; Emadi, A. Energy storage systems for automotive applications. IEEE Trans. Ind. Electron. 2008, 55, 2258-2267. [CrossRef]

5. Omar, N.; Daowd, M.; Van Den Bossche, P.; Hegazy, O.; Cooseemans, T.; Van Mierlo, J. Rechargeable energy storage systems for plug-in hybrid electric vehicles-Assessment of electrical characteristics. Energies 2012, 5, 2952-2988. [CrossRef] 
6. Andrea, D. Battery Management Systems for Large Lithium Ion Battery Packs; Artech House: Boston, MA, USA, 2010.

7. Barré, A.; Deguilhem, B.; Grolleau, S.; Gérard, M.; Suard, F.; Riu, D. A review on lithium-ion battery ageing mechanisms and estimations for automotive applications. J. Power Sources 2013, 241, 680-689. [CrossRef]

8. Bruen, T.; Hooper, J.M.; Marco, J.; Gama, M.; Chouchelamane, G.H. Analysis of a battery management system (BMS) control strategy for vibration aged nickel manganese cobalt oxide (NMC) Lithium-Ion 18650 battery cells. Energies 2016, 9, 255. [CrossRef]

9. He, H.; Xiong, R.; Fan, J. Evaluation of lithium-ion battery equivalent circuit models for state of charge estimation by an experimental approach. Energies 2011, 4, 582-598. [CrossRef]

10. Hu, Y.; Yurkovich, S.; Guezennec, Y.; Yurkovich, B.J. A technique for dynamic battery model identification in automotive applications using linear parameter varying structures. Control Eng. Pract. 2009, 17, 1190-1201. [CrossRef]

11. Chen, D.; Jiang, J.; Li, X.; Wang, Z.; Zhang, W. Modeling of a pouch lithium ion battery using a distributed parameter equivalent circuit for internal non-uniformity analysis. Energies 2016, 9, 865. [CrossRef]

12. Castano, S.; Serrano-Jimenez, D.; Sanz, J. BMS influence on Li-ion Packs Characterization and Modeling. In Proceedings of the IEEE 16th International Conference on Environmental and Electrical Engineering (EEEIC), Florence, Italy, 7-10 June 2016.

13. Shafiei, A.; Momeni, A.; Williamson, S. Battery modeling approaches and management techniques for plug-in hybrid electric vehicles. In Proceedings of the Vehicle Power and Propulsion Conference (VPPC), Chicago, IL, USA, 6-9 September 2011.

14. Chen, M.; Rincon-Mora, G.A. Accurate Electrical battery model capable of predicting runtime and I-V performance. IEEE Trans.Energy Convers. 2006, 21, 504-511. [CrossRef]

15. Xia, B.; Wang, H.; Wang, M.; Sun, W.; Xu, Z.; Lai, Y. A new method for state of charge estimation of lithium-ion battery based on strong tracking cubature kalman filter. Energies 2015, 8, 13458-13472. [CrossRef]

16. Castano, S.; Gauchia, L.; Voncila, E.; Sanz, J. Dynamical modeling procedure of a Li-ion battery pack suitable for real-time applications. Energy Convers. Manag. 2015, 92, 396-405. [CrossRef]

17. Buller, S.; Thele, M.; De Doncker, R.W.; Karden, E. Impedance-based simulation models of supercapacitors and $\mathrm{Li}$-ion batteries for power electronic applications. In Proceedings of the Industry Applications Conference, Salt Lake City, UT, USA, 12-16 October 2003.

18. Plett, G. Extended Kalman filtering for battery management systems of LiPB-bases HEV battery packs. Part 2. Modeling and identification. J. Power Sources 2010, 134, 262-276. [CrossRef]

19. Zhu, L.; Sun, Z.; Dai, H.; Wei, X. A novel modeling methodology of open circuit voltage hysteresis for LiFePO4 batteries based on an adaptive discrete Preisach model. Appl. Energy 2015, 155, 91-109. [CrossRef]

20. Cooper, K.; Smith, M. Electrical test methods for on-line fuel cell ohmic resistance measurement. J. Power Sources 2006, 160, 1088-1095. [CrossRef]

21. Andre, D.; Meiler, M.; Steiner, K.; Walz, H.; Soczka-Guth, T.; Sauer, D.U. Characterization of high-power lithium-ion batteries by electrochemical impedance spectroscopy. I. Experimental investigation. J. Power Sources 2011, 196, 5334-5341. [CrossRef]

22. Castano, S.; Gauchia, L.; Sanz, J. Effect of packaging on supercapacitors string modeling: Proposal of a functional unit defined around the balancing circuit. IEEE Trans. Compon. Packag. Manuf. Technol. 2013, 3, 1390-1398. [CrossRef]

23. Bouscayrol, A. Different types of hardware-in-the-loop simulation for electric drives. In Proceedings of the IEEE International Symposium on Industrial Electronics, Cambridge, UK, 30 June-2 July 2008.

24. Gauchia, L.; Sanz, J. A per-unit hardware-in-the-loop simulation of a fuel cell/battery hybrid energy system. IEEE Trans. Ind. Electron. 2010, 57, 1186-1194. [CrossRef]

25. Mahmood, F.; Hooshyar, H.; Vanfretti, L. Extracting steady state components from synchrophasor data using Kalman filters. Energies 2016, 9, 315. [CrossRef]

26. Bouscayrol, A.; Lhomme, W.; Delarue, P.; Lemaire-Semail, B.; Aksas, S. Hardware-in-the-loop simulation of electric vehicle traction systems using energetic macroscopic representation. In Proceedings of the IECON 2006-32nd Annual Conference on Industrial Electronics, Paris, France, 6-10 November 2006.

(C) 2017 by the authors. Licensee MDPI, Basel, Switzerland. This article is an open access article distributed under the terms and conditions of the Creative Commons Attribution (CC BY) license (http:/ / creativecommons.org/licenses/by/4.0/). 